Article

\title{
Dealing with Risk in Child and Family Social Work: From an Anxious to a Reflexive Professional?
}

\author{
Eline Vyvey ${ }^{*},{ }^{\dagger}$, Rudi Roose ${ }^{\dagger}$, Lieselot De Wilde ${ }^{\dagger}$ and Griet Roets ${ }^{\dagger}$ \\ Department of Social Welfare Studies, Ghent University, Henri Dunantlaan 2, Ghent 9000, Belgium; \\ E-Mails: rudi.roose@ugent.be (R.R.); lieselot.dewilde@ugent.be (L.D.W.); griet.roets@ugent.be (G.R.) \\ † These authors contributed equally to this work. \\ * Author to whom correspondence should be addressed; E-Mail: eline.vyvey@ugent.be; \\ Tel.: +32-9-264-6285.
}

External Editor: Nigel Parton

Received: 26 August 2014; in revised form: 26 September 2014 / Accepted: 9 October 2014 /

Published: 16 October 2014

\begin{abstract}
The rhetoric of risk has become a prominent issue in the field of child and family social work. As a consequence, an emerging politics of fear has re-oriented this field towards managing, controlling, and securing social work practice against risk, rather than responding meaningfully to the needs and concerns of children and families. In the available body of research, it is argued that this general tendency creates "anxious" professionals. As a response, different scholars refer to the need to "speak back to fear". In this article, we analyze this claim in the context of a currently ongoing large-scale policy reform, named Integrated Youth Care (IYC), in the field of child welfare and protection in Flanders (the Dutch speaking part of Belgium). The debate on dealing with risk is often limited to an organizational and methodological discussion. We assert that we should reorient this debate and make a plea for a radical approach of applying a welfare perspective in child welfare and protection.
\end{abstract}

Keywords: risk; youth care; child and family social work; child welfare; child protection 


\section{Introduction}

The concept of risk recently received a lot of attention in human services management, frontline practice, and the social policy domain of child and family social work [1-4]. There is an emergent consensus in research on child and family social work that there has been a shift in emphasis across the Western world from child welfare to child protection, with a great deal of time being absorbed by the investigation of alleged abuse [5,6]. In different countries, the major impetus for this focus on risk in social work is rooted in political and cultural responses to tragedies (in particular, cases involving extreme negative outcomes for children). Over the last few years, an exponential growth of policy focused on children and young people has emerged. Especially in the UK, a public concern emerged due to the death of Victoria Climbie, an eight-year-old girl who was abused by her guardians despite family contact with a large range of health, welfare, and child protection services. The death of Peter Connely (named "Baby P”) is another high profile case [7]. At the time of his death at the age of seventeen months, he had a broken back and some fifty injuries, even though the social worker saw the child on a home visit four days before he died [8]. This preoccupation with risk, however, is not just a "British disease" [7]. Inquiries into the fatal abuse of children have recently also taken place in other European countries, for instance in the Netherlands. In 2004, the three-year-old Savanna died in the Netherlands after a long period of serious abuse mainly by her mother, despite being under the supervision of child protection services. This case led to the prosecution of the frontline social worker who was charged with supervising Savanna. The death of Savanna impacted Dutch society deeply, and therefore, referral is made to the "Savanna effect", as several changes in child welfare and protections policy and practice were made with the intention of making earlier interventions by child protection workers possible in families. The responsibility for such cases was not only attributed to the actual abusers, but also to the agencies and professionals who had failed to prevent such outcomes [9]. In some countries, these cases even led to official inquiries into professional practice after child abuse tragedies. The main aim of these inquiries was to improve child protection in order to reduce the risk of more infant casualties [10,11].

As a result, these tragic cases of child abuse and neglect strengthened the idea that risk should be perceived in negative and fearful terms, rather than in positive terms [12]. This solely negative approach to risk can, according to the authors of this article, have a deep impact on professional practices, as the climate of fear affects professionals who work with the children and families that are considered to be at risk $[13,14]$. Consequently, social workers fear for their physical and mental well-being, for being blamed when things go wrong, and for an undermining of the integrity of their profession. In that sense, this culture of fear, as cultivated by society, can drive frontline workers to become anxious professionals [15]. As such, perceiving risk in more positive terms as an impulse for change and opportunities seems to have disappeared in social work. These issues tend to create moral dilemmas, which undermine social work's capacity to respond meaningfully, purposefully, and creatively to risk situations [16]. Fear, panic, and the need to control have overtaken and undermined discussions about the courage and creative thinking necessary to take risks in social work practices [2]. Therefore, it is argued that social work must "speak back" to the culture of fear. Since notions of risk operate as powerful discursive constructs for shaping social work knowledge and practice in child welfare and protection, Stanford [17] suggests that it is necessary to explore the ways in which social 
workers can "speak back" to the "culture of fear" that is engendered by the rhetoric of risk as an integrated dimension of social work practice. In that vein, social workers need to understand that the profession inherently involves risk-taking, and consequently, there is an urgent need for reflection on the way social workers can act in meaningful ways when attending to risk-related matters during their interventions [17]. In this contribution, we discuss the idea of speaking back to fear in the context of a currently ongoing reform, named Integrated Youth Care, in the field of child welfare and protection in Flanders (the Dutch speaking part of Belgium). Although child and family social work in Flanders still focuses on elements of child welfare, the focus on risk and on elements of child protection, an orientation characterized by a primary concern to protect children from abuse, recently became increasingly dominant. While social workers may support a child welfare orientation in practice [18], this holds the risk of strengthening professional and organizational anxiety in managing child protection risks, whereby bureaucratic and defensive practices prevail [19].

In this contribution, we first look at historical dimensions of risk, and more in particular at the notion of the "child at risk", as an ambiguous social construct, since there are lessons to be learned from the ways in which the notion of the "child at risk" has changed as an ever-evolving concept in child welfare and protection practices. Second, we link the notion of risk to the debate about a child welfare or child protection perspective. Third, we discuss these different approaches in relation to the reform of Flemish practices concerning child welfare and protection, which is called "Integrated Youth Care”. Although child and family social work is driven by a child welfare approach, Integrated Youth Care also adopts an increasingly prominent protectionist approach. Fourth, we argue that different underlying assumptions are at stake in the policies and practices of Integrated Youth Care in dealing with risk: the logic of risk avoidance and the logic of risk taking. We conclude with some reflections, arguing that the dominant discourse on risk requires reflexive rather than anxious professionals. The anxious professional works according to the logic of risk avoidance, implementing an approach in which social workers try to avoid risks rather than maximizing their engagement towards complex situations, which is typical for the reflexive practitioner, who works in the vein of a logic of risk-taking. Finally, we argue that speaking back to fear demands a radical welfare approach in child and family social work with children, youngsters, and their families.

\section{Risk as an Ambiguous Social Construct}

Child and family social work in Flanders (the Dutch speaking part of Belgium) has recently been reformed into a system of Integrated Youth Care (IYC). In this reform, a stronger attention for risk is coming to the fore. This is in line with development in many Western welfare states, as a much closer concern emerged recently about what causes harm to children, indicating a renewed interest and priority given to social work in the field of child welfare and protection to intervene in alarming situations [20]. The rhetoric of risk, however, is not a new or particularly 21st century phenomenon, because growing up has historically been linked to the specific dangers and threats that young people could either be subjected to ("being endangered" or "at risk") or pose themselves ("being a danger" or “a risk”) [21]. The specific term, "children at risk", pops up for the first time in the first half of the 20th century, although the origin of the discourse is even older. Most authors situate the birth of the "child at risk" at the beginning of the 19th century in the realm of an increasing interest of 
philanthropists, who paid special attention to the marginal position of the child from lower societal classes. In the spirit of that age, attention went primarily to children who grew up in misery, desolation, and neglect, and who were regarded as morally endangered [22,23]. This kind of upbringing would allegedly provide a so-called breeding ground for socially deviant behavior and juvenile delinquency. As a result, different kinds of solutions were considered to save these so-called "gangs of unsupervised children", such as orphans, foundlings, and abandoned children [23]. As such, a public concern emerged to protect society, as well as these "children at risk". The underlying assumption implied that children at risk needed to be protected against their so-called "dangerous" and "irresponsible” parents, based on a legal ground of "child protection”, by removing them (temporarily) from their parents [22]. This tendency to speak of children and families as being "at risk" led to a climate in which the legitimacy of government intervention would be broadly accepted [24].

Despite the widely acclaimed improvement of our standard of living during the last century and countless interventions, we find that the group of "children at risk" has not "resolved" itself. On the contrary, in the present day, we observe a countless number of potential risks that children and young people can pose or be exposed to. In this context, the sociologist Turmel [25] refers to an important shift within the "risk discourse": from the potential delinquent child as the encapsulated form of the "child at risk" towards the "normal child". He argues that this process started at the end of the 19th century and entails an intensive search for methods, procedures, and techniques to observe children and to register the collected data, on an increasingly professional and scientific level [26]. Under the influence of two key processes in the domain of education and child rearing, technologization and professionalization, the notion of the "normal child" (as in the average child), became gradually more central in the course of the 20th century. Therefore, the initial hope of reducing the number of at risk children fades away, since the group only grows: the criteria for determining when a child is or is not at risk expands, and new categories leading to new risks and risky situations occur. In international circles, the notion of the "child at risk" is currently considered as a strikingly ambiguous and ever-evolving concept [27]. We see risks and dangers everywhere against which we must protect children and young people. As Dekker ([24], p. 18) asserts, "we can easily speak of 'the century of the child at risk' since 'the history of children at risk is a story of expansion. It is a story of the birth time and again of new categories of children at risk together with new measures and institutions to tackle these new risks'”. As a result of these developments within the field of child welfare and protection, the assumption is raised during the 20th century that any problematized deviation from the norm would be a manageable given. The assumption strongly lives that we can and should unravel any risk, which is calculated on the basis of a set of abstract factors [28]. A so-called "control illusion", or what is often called "the scientification of risk" [23], implies that technological advances and the deployment of experts make it feasible to control every risk. The result is an excessive collective astonishment when something goes wrong after all. This urge for risk management seems widespread. As Guldberg ([28], p. 85) writes, “once overworrying is institutionalized, the list of potential problems facing children goes on and on”. In that sense, today's prevailing moral panics regarding children and young people have never been so excessive, and several authors emphasize that we currently live in a true "culture of fear". She [28] states in "Reclaiming childhood" that we live in a "safety obsessed culture," in which the "better safe than sorry idea” is ever-present, and prevention and control accordingly are keywords in mitigating all possible risks. Hence, in light of the reform of youth care in 
Flanders, it is important to keep in mind that the notion of the "child at risk" is extremely complex and ambiguous, since it can be considered and constructed in radically different ways in child welfare and protection practices [20,29,30]. As Parton ([31], p. 855) asserts, "new and sometimes competing ideas about risk to children and the best ways of addressing these" are currently at stake. This construction process might involve major challenges to professional (risk) assessment and intervention [17,30]. As Hood ([30], p. 6) asserts, the current concern that families may be a locus of risks to children "obviously puts great pressure on assessment and decision making; making the wrong prediction about what will happen can have tragic consequences”.

\section{A Child Welfare or Child Protection Perspective}

In the field of child welfare and protection, several authors [18,32,33] have identified differences between child protection and child welfare orientations. From a child protection perspective, the focus typically lays on investigative procedures to legitimize rather intrusive interventions, whereas, from a child welfare perspective, problems are located in the broader social context in order to realize child welfare [34]. In relation to the issue of dealing with risk, the child protection perspective gives priority to protecting children against abuse. The goal is to prevent damage to children, and to reduce the risks of harm. Social work practice therefore is defined mainly as an investigation, conducted to detect potential harm in family life situations. By contrast, a child welfare approach is "characteriszd by a tendency to understand acts, or circumstances, thought of as harmful to children, in the context of psychological or social difficulties experienced by families” ([18], p. 934).

In the Belgian context, this child welfare perspective is firmly rooted in social policy, in which child welfare and protection are perceived as a "comprehensive array of policies that form a pyramid" ([35], p. 205). From an organizational perspective, this is manifest in a range of interventions; from a broad array of indirect preventative child welfare services (such as a range of family support oriented services) to, at the top of the pyramid, more specific and reactive child protection services. Hence, a leading principle in child welfare and protection in Belgium is subsidiarity, "which basically refers to the idea that more investments at the base will reduce the need for interventions at the apex” ([35], p. 205). As such, the child welfare perspective in services is strengthened in order to prevent the intake of children and youngsters in the system of child protection services [33]. The rationale is that child protection services and practices are seen as more intrusive and expensive than the services and practices that are underpinned by this child welfare perspective, and therefore should be avoided where possible [34]. In the context of the large-scale social policy reform of Integrated Youth Care, entering child protection services is currently only possible through two specific organizations, which function as gatekeepers (since they have the mandate to intervene in a more mandatory way or to make references youth judges): the Youth Care Offices and the Confidential Centers for Child Abuse and Neglect. The Youth Care Offices provide support to social workers in cases of risk situations and the Confidential Centers for Child Abuse report and investigate particular suspicions of child abuse. In these practices, the concept of "societal necessity" is introduced as an underlying ground that legitimizes intervention. Dealing with societal necessity means coping with alarming risk situations or environments when someone feels the need or formulates the expectation that youth care is exigent for the minor and/or his family [35]. 
Although one might argue that child and family social work is principally driven by a child welfare logic, it is equally valid to observe that a mainly protectionist approach has been implemented. First, welfare-oriented organizations in the field of child welfare and protection are driven by a logic of prevention, in a sense that these organizations are oriented towards the prevention of the use of social service delivery itself, rather than towards preventing social problems and the broadening of social support (e.g., housing, poverty work). The prevention of child protection interventions in Belgium has been historically a key idea in the development of the child welfare and child protection system and has become more influential during the latter half of the twentieth century, so that scarce welfare state resources could be directed to where, in theory, they were most needed. While hoping to make the child protection system redundant and residual, social policy also aimed to reduce the number of referrals to non-directly accessible child protection services [22]. Hence, although the welfare approach is still very dominant in the policy framework, this welfare approach is very much driven by a logic of protection. Thus, child welfare organizations perform their functions from a negative perspective that prioritizes the prevention of more intrusive interventions, rather than the provision of support [30].

\section{Integrated Youth Care}

This preventative rhetoric of risk recently acquired a central role in the framework of Integrated Youth Care. This is a cross-sectorial policy program of the Flemish government, which aims at a coordinated approach for helping troubled children and young people and their families [36,37]. This reform resulted from the activities of a Parliamentary Ad Hoc Commission on Youth Care during 1998. As the result of this think tank, it was stated that the fragmentation of child protection and child welfare services, reflected in the striking gaps and overlaps in the provision of services, was leading to conspicuous ineffectiveness and inefficiency. Launched as a large-scale policy-driven organizational reform of child and family services in the Decree on Integrated Youth Care of 2004, the development of Integrated Youth Care required the inter-sectorial reorganization of a wide diversity of ambulant, as well as residential, welfare services for children and youngsters (0-18 years-old), covering seven different sectors, to improve the effectiveness and efficiency of child and family services [38]. The central aim of Integrated Youth Care was summarized as "rendering an integrated assistance to the minor and/or the minor and his/her relatives to safeguard their scope to develop and to improve their well-being” ([39], p. 11). As such, social policy makers decided to aim at organizing the existing supply of social work services into clear-cut "modules”, which define what services and organizations do, how they do it, and for whom [40]. This is directed at the realization of a transparent and inter-sectorial joining-up of networks of social service delivery to serve customers, based on the establishment of a flexible and demand-driven integration of social work modules in service delivery. This organizational reform also stipulates that the activities of different child and family services are geared to each other, in order to cover existing gaps and to prevent overlaps in service provision [41].

In this reform, child welfare organizations are urged to take more responsibility in risk situations. In the social policy framework of Integrated Youth Care, "risk" is "a situation that threatens the development of a minor because his mental, physical or sexual integrity or that of one or more members of his family is affected, or because his emotional, moral, intellectual, and social development opportunities are threatened, which make youth care socially necessary” ([41], p. 133). 
From this perspective, prevention is likewise focused on the individual child rather than on preventing or tackling broader social problems [42].

\section{Dealing with Risk: The Beginning or the End of Dialogue}

Hence, in the framework of Integrated Youth Care, child welfare and child protection workers are increasingly required to deal with complexity and risk, and are increasingly required to make decisions about potential threats as "risk positions individuals and governments and citizens in relationships dominated by suspicion, and attitudes and moralities of protectionism and responsibilization as an inherent part of their job” ([17], p. 1066). In that light, risk assessment and management have become part of ongoing processes of professionalization in the complex world of child welfare and protection [43]. Given increased demands for public accountability, approaches to risk assessment and management currently vary between standardizations, technical and diagnostic tools, checklists and procedures, and more qualitative, open-ended, and dialogic ways to assess and interpret the potentiality of risk [44]. However, as mentioned in the introduction, there is currently no clarity about the question of how social workers can act in meaningful ways when considering and dealing with risk in their interventions, and how they can possibly "speak back to fear”. As such, how social work in Integrated Youth Care will deal with risk and which kind of logic will drive them is an important issue: one may adopt either a logic of risk avoidance, where accountability for what social workers are doing is situated outside practice, or of risk taking, where accountability for what social workers are doing is positioned within the practice [45].

\subsection{Risk Avoidance: The End of Dialogue}

It is stated that the contemporary societal obsession with danger and risk minimization [13] has reoriented social work towards managing and securing their practice against risk, instead of responding meaningfully to the needs of children and families [17]. Whilst much of the practice of professionals in child and family social work is necessarily based on the development of a mutual understanding and trust through client contact, the assumption of risk has resulted in an expansion of risk management practices. Management systems develop regulatory systems and routines intended to standardize practice and thereby limit variations in practice [46]. Most of these strategies are based on a restricted approach to risk that emphasizes hazard assessment and safety issues. There is limited evidence of broader integrated approaches to risk management [2]. The practice of risk control changes the type and nature of child and family social work from one of trusting relationship built over time to technological interventions characterized by risk-based classification, assessment, and short-term intervention [14]. The shift towards social work as a possible instrument of surveillance and control can also be situated within a changing discourse on responsibility. In neoliberal contexts, responsibility tends to evolve as a downward spiral [47], as it is increasingly shifted from the state to the individual [48]. In this development, "more responsibility for the individual (citizen)" rather needs to be interpreted in terms of a responsibilization of the individual in which the conditions of being responsible are clearly formulated by the state [49]. The state defines a social problem, and the individual is expected to play a central role in the solution for that socially constructed problem. Who is not willing to be “responsible”, will be forced (and even punished); who is not able to be "responsible” will be helped. 
In this, the state presents itself as a companion of the individual (citizen), but at the same time it defines what needs to be regarded as responsible behavior [50]. The security that risk technology suggests is seductive [44]. However, if we look at risk and danger in such a defensive way [51], accountability for the actions of social workers is placed outside the concrete situation, because these risk assessment instrument reduce decision-making options and minimize discretion [43]. The growing trend to establish tools, procedures, and protocols seem to indicate that social workers can resolve the complexity that is typical for social work and can protect themselves against radical criticism when things go wrong with children in families. Important in this context, however, is the awareness that an anxious professional remains a powerful professional: his fear drives the policy space into a risk avoiding direction [15] and paradoxically, "risk avoidance carries the danger of creating new risks, both by heightening social workers' anxiety and vulnerability, and by prompting them to identify new areas of risk in users’ lives, which can lead them to adopt a more controlling approach” ([45], p. 227).

\subsection{Risk Taking: A Starting Point for Dialogue}

Social workers might also deal with risk more reflexively [30,49,52]. Here, accountability for the ways in which social workers are dealing with risk is judged on the basis of the engagement of social workers in the concrete situations in which they intervene. "Rather than try to calculate the incalculable, social workers need to regain their former status as experts in uncertainty" ([45], p. 228). This implies that social workers do more than implement a strengths-based perspective and organize a dialogical assessment. For instance, to objectify risk situations in Integrated Youth Care in Flanders, a methodology is promoted that aspires to objectify "risk security": Signs of Safety. This so-called "objective” diagnosis is seen as a prerequisite for good care. Nevertheless, this assumption is not necessarily evident. First of all, proper care does not inherently coincide with the quality of the diagnosis, but also depends on the quality of the engagement towards young people and their families [21]. Second, child welfare work is about commitment, being present, and the development of a shared responsibility of social workers and parents [30]. This also involves the engagement to challenge the dominant risk discourse and to question one's own constructions and ideas. According to this approach, risk assessment is viewed as a starting point for dialogue instead of an end of dialogue. According to McLaughlin [13], risk assessment in social work is not a precise actuarial model in which the probability of unwanted outcomes can be precisely determined. It goes beyond that. Each individual is also influenced by their interactions with the organization in which they work and the wider society in which they live [13]. Most risk instruments ignore the importance of moving beyond procedures to examine the detail of how practitioners enact risk technologies [53]. According to Ferguson [8], realizing high quality in child protection involves the skillful management of actively engaging with children and their environment. The relational aspect of practice creates a range of practical and moral dilemmas that are difficult to systematize [48]. Hence, while professionals are concerned about hazard and harm, they also recognize the need for risk-taking [2]. This implies that the possibility of error and mistake, and also of public debate, about the assessment of risk is essential on an organizational as well as on an inter-organizational level in social work services, because even mistakes — which are often kept hidden — can serve as an opportunity to learn. As Roose [54] argues "social workers need space to make mistakes and the opportunity to have open-minded discussions 
about these mistakes because, paradoxically, in many cases, it is the only way to develop a responsive approach to the client and to enable social workers to find new ways to face the complexity of problems. The irony of situations, and particularly of mistakes, might enable social workers to consider mistakes as a point of departure for further actions” ([54], p. 12).

\subsection{An Example: The Use of Consultation}

As an example of the different perspectives that social workers can develop in dealing with risk, we refer to the role and use of the practice of "consultation”, as one of the core missions of the Youth Care Office in Flanders. The main aim of the Youth Care Office is to provide consultation to social workers and youth care services in risk situations, where social workers no longer feel comfortable in dealing with situations of risk within their own practice. Hence, they can ask the Youth Care Office for support and advice in dealing with the situation [25].

We notice in practice that social workers make use of this possibility of consultation in different ways. Some use it defensively [51]. This practice is sometimes used, for example, in the hopes of legitimizing the ending of the engagement towards the situation and the passing of the case to other social work services [21]. Thus, accountability is placed outside the concrete situation as the end of dialogue [43,45], as the demand for a consult is mainly used to prevent the possibility of error [55].

Consultation is, however, also used in more reflexive ways, aimed at broadening the engagement in situations of risk $[30,49,53]$. Here, accountability is placed inside the concrete situation and the perception of a situation as risky is viewed as a starting point for dialogue. Social workers accept their responsibility for risk taking and have a great commitment to each specific situation, including the commitment to question their own construction of risk. As such, child and family social work involves travelling into the unknown. Rather than understanding risk in social work as only danger and in terms of fear of blame for things going wrong, the consult might support the social workers to recast notions of risk in more positive terms of opportunity, courage, resilience, skill, and creativity [8].

\section{Concluding Reflections: From an Anxious to a Reflexive Professional?}

In this contribution, we argued that a more protectionist approach, driven by a focus on risk, has become increasingly central in Flemish practices of child welfare and protection. However, we also argued that social workers can deal with this development in diverse ways, be it defensive or reflexive. In that vein, Fargion [32] refers to the features of a child welfare approach, in which professionals are mainly seen as strong and reflexive professionals; whereas a child protection perspective implies that professional discretion is limited and social workers are easily distrusted. We argue that the dominant discourse on risk requires reflexive rather than anxious professionals. Anxious professionals work according to a logic of risk avoidance rather than maximizing their engagement towards complex situations, which is typical for the reflexive practitioner, who works in the vein of a logic of risk taking.

In present-day, this is not the case in Flanders, as the media and the profession seem to respond to tragic incidences in a more serene manner than in other countries, such as the UK and the Netherlands [56]. Nevertheless, social workers in Flanders are in fact influenced by these developments. Albeit, in our view it is deeply problematic that the debate on dealing with risk in Flanders mainly refers to the management of child welfare and protection and to the development of objective and technical 
methods to deal with risk (such as signs of safety [57]). The attention currently goes to the questions of whether risk can be avoided, how the transition from child welfare to child protection can be prevented, or, if unavoidable, how the transition can be organized [30]. Little or no attention goes to the underlying question from which child welfare and protection are realized: what are our ideas about risk and about good social work? What do we consider to be a strong professional? What kind of responsibilities for whom does this involve, etc.? Hence, a thorough debate on risk-taking stays under the radar.

Although social workers in reality construct multiple manners to speak back to fear [7], we argue that dealing with risk should not be reduced to a debate about organizational or methodological issues. Therefore, we argue that a child welfare perspective should be implemented as radically as possible. This discussion should go beyond the plea for more child welfare organizations to prevent protectionist interventions. It also goes beyond a focus on individual social workers and organizations. It should include a diversity of questions with respect to the underlying perspective of child welfare and protection practices, and should ultimately refer to questions concerning the kind of society we want to live in and the place of social work in the welfare state.

In our view, social work needs to consider its responsibility to interrupt the conservative ethos of negative constructs of risk, and enable its capacity to take risks in favor of the client, driven by the question of how to deal with risk without answering risk-related dilemmas with fear [17].

\section{Author Contributions}

Eline Vyvey was the primary writer and editor of the paper, together with her supervisor Rudi Roose who participated in the whole process of the literature review, preparing the paper and finishing the manuscript. Lieselot De Wilde and Griet Roets wrote different paragraphs in the paper while strengthening the coherence of the paper and participated in every step of preparing this manuscript.

\section{Conflicts of Interest}

The authors declare no conflict of interest.

\section{References}

1. Barry Goldson. “'Children in Need' or 'Young Offenders'? Hardening ideology, organizational change and new challenges for social work with children in trouble.” Child and Family Social Work 5 (2000): 255-65.

2. Andy Alaszewksi, and Helen Alaszewski. "Towards the creative management of risk: Perceptions, practices and policies.” British Journal of Learning Disabilities 30 (2002): 56-62.

3. Derrick Armstrong. "A risky business? Research, Policy, Governmentality and Youth Offending." Youth Justice 4 (2004): 100-17.

4. Hazel Kemshall. "Risks, rights and justice: Understanding and responding to youth at risk.” Youth Justice 8 (2008): 21-37.

5. Nigel Parton, David Thorpe, and Corinne Wattam. Child Protection: Risk and the Moral Order. Basingstoke: Macmillan Press, 1997, p. 276. 
6. Jonathan Scourfield, and Ian Welsh. "Risk, Reflexivity and Social Control in Child Protection: New Times or Same Old Story?” Critical Social Policy 23 (2003): 98-120.

7. Joanne Warner, and Elaine Sharland. “Editorial.” British Journal of Social Work 40 (2010): 1035-45.

8. Harry Ferguson. "Walks, Home Visits and Atmospheres: Risk and the Everyday Practices and Mobilities of Social Work and Child Protection.” British Journal of Social Work 40 (2010): 1100-17.

9. Tirza Kuijvenhoven, and Willem J. Kortleven. "Inquiries into Fatal Child Abuse in the Netherlands: A Source of Improvement?” British Journal of Social Work 40 (2010): 1152-73.

10. Nigel Parton. "Risk, Advanced Liberalism and Child Welfare: The Need to Rediscover Uncertainty and Ambiguity.” British Journal of Social Work 28 (1998): 5-27.

11. Peter Lachman, and Claudia Bernard. "Moving from blame to quality: How to respond to failures in child protective services.” Child Abuse \& Neglect 30 (2006): 963-68.

12. David Denney. "Violence and Social Care Staff: Positive and Negative Approaches to Risk." British Journal of Social Work 40 (2010): 1297-313.

13. Ken McLaughlin. Social Work, Politics and Society: From Radicalism to Orthodoxy. Bristol: Policy Press, 2008, p. 192.

14. Stephen A. Webb. Social Work in a Risk Society: Social and Political Perspectives. Houndsmills: Palgrave Macmillan, 2006, p. 256.

15. Maria Bouverne-De Bie. "Over angstige en sociale professionals." Paper presented at the Association Research Group Pedagogy of Social Work, Ghent University Association, Radboud University and HAN University of Applied Sciences, Ghent University, Ghent, Belgium, 12 December 2008.

16. Mike Titterton. Risk and Risk Taking in Health and Social Welfare. London: Jessica Kingsley Publishers, 2006, p. 160.

17. Sonya Stanford. “'Speaking Back’ to Fear: Responding to the Moral Dilemmas of Risk in Social Work Practice.” British Journal of Social Work 40 (2010): 1065-80.

18. Matthew Colton, Charlotte Drury, and Margaret Williams. Children in Need: Family Support under the Children Act 1989. Aldershot: Avebury, 1995, p. 248.

19. Trevor Spratt. "The Influence of Child Protection Orientation on Child Welfare Practice.” British Journal of Social Work 31 (2001): 933-54.

20. Ingrid Lohmann, and Christine Mayer. "Lessons from the history of education for a 'century of the child at risk'.” Paedagogica Historica: International Journal of the History of Education 45 (2009): 1-16.

21. Cynthia Anne Connolly. Saving Sickly Children: The Tuberculosis Preventorium in American Life, 1909-1970. New Brunswick: Rutgers University Press, 2008, p. 200.

22. Juliane Jacobi. "Between charity and education: Orphans and orphanages in early modern times." Paedagogica Historica: International Journal of the History of Education 45 (2009): 51-66.

23. Paul Smeyers. "Child rearing in the 'risk' society: On the discourse of rights and the best interests of a child.” Educational Theory 60 (2010): 271-84.

24. Jeroen J. H. Dekker. "Children at risk in history: A story of expansion.” Paedagogica Historica: International Journal of the History of Education 45 (2009): 17-36.

25. André Turmel. A Historical Sociology of Childhood: Developmental Thinking, Categorization and Graphic Visualization. Cambridge, UK: Cambridge University Press, 2008, p. 376. 
26. Christine Mayer, Ingrid Lohmann, and Ian Grosvenor. Children and Youth at Risk: Historical and International Perspectives. Frankfurt am Main: Peter Lang, 2009, p. 316.

27. Robert Castel. "From dangerousness to risk.” In The Foucault Effect: Studies in Governmentality. With Two Lectures by and an Interview with Michel Foucault. Edited by Graham Burchell, Colin Fordon and Peter Millger. Chicago: The University of Chicago Press, 1991, pp. 281-98.

28. Helene Guldberg. Reclaiming Childhood: Freedom and Play in an Age of Fear. New York: Routledge, 2009, p. 216.

29. Sylvia Schafer. Children in Moral Danger and the Problem of Government in Third Republic France. Princeton: Princeton University Press, 1999, p. 232.

30. Rick Hood. “Complexity and Integrated Working in Children's Services.” British Journal of Social Work 44 (2014): 27-43.

31. Nigel Parton. "Child protection and safeguarding in England: Changing and competing conceptions of risk and their implications for social work.” British Journal of Social Work 41 (2011): 854-75.

32. Silvia Fargion. "Synergies and Tensions in Child Protection and Parent Support: Policy Lines and Practitioners’ Cultures.” Child and Family Social Work 19 (2014): 24-33.

33. Rudi Roose, Griet Roets, and Tineke Schiettecat. "Implementing a strengths perspective in child welfare and protection: A challenge not to be taken lightly.” European Journal of Social Work 17 (2014): 3-17.

34. Neil Gilbert. Combating Child Abuse: International Perspectives and Trends. New York: Oxford University Press, 1997, p. 255.

35. Kristof Desair, and Peter Adriaenssens. "Policy toward child abuse and neglect in Belgium: Shared responsibility, differentiated response.” In Child Protection Systems. Edited by Neil Gilbert, Nigel Parton and Marit Skivenes. New York: Oxford University Press, 2011, pp. 204-22.

36. Cocops. Available online: http://www.cocops.eu/wpcontent/uploads/2014/02/Belgium_Health_ Integrated_Youth_Care_fin1.pdf (accessed on 1 June 2014).

37. Jean-Pierre Vanhee. Dat verandert de zaak. Een bijdrage tot de articulatie van Integrale jeugdhulp. Brussel: Politeia, 2014, p. 246. (In Dutch)

38. Griet Roets, Rudi Roose, and Tineke Schiettecat. "Reconstructing the foundations of joined-up working.” British Journal of Social Work, 2014, in press.

39. Dirk Broos, and Veronigue Grossi. Strategisch Plan Integrale Jeugdhulpverlening. Brussel: Ministerie van de Vlaamse Gemeenschap, Departement Welzijn, Gezondheid en Cultuur, 2000, p. 11. (In Dutch)

40. Ludo Serrien. Modulering is meer dan een wegwijzer. Handboek Integrale jeugdhulp. Brussel: Politeia, 2011, pp. 1-10. (In Dutch)

41. Vlaams Parlement. Decreet integrale jeugdhulp. Brussel: Vlaams Parlement, 2013, pp. 5-227. (In Dutch)

42. Emily Kedell. "The ethics of predictive risk modelling in the Aotearoa/New Zealand child welfare context: Child abuse prevention or neo-liberal tool?” Critical Social Policy, 2014, in press.

43. Karen Broadhurst, Chris Hall, Dave Wastell, Sue White, and Andy Pithouse. "Risk, Instrumentalism and the Humane Project of Social Work: Identifying the Informal Logics of Risk Management in Children's Statutory Services.” British Journal of Social Work 40 (2010): 1046-64. 
44. Tom Horlick-Jones. "Informal logics of risk: Contingency and modes of practical reasoning." Journal of Risk Research 8 (2005): 253-72.

45. Kirsten Stalker. "Managing Risk and Uncertainty in Social Work.” Journal of Sociaal Work 3 (2003): 211-33.

46. Fran Tonkiss, and Andrew Passey. "Trust, confidence and voluntary organisations: Between values and institutions.” Sociology 33 (1999): 257-74.

47. Gerald Cradock. "The responsibility dance: Creating neoliberal children.” Childhood 14 (2007): 153-72.

48. Nina Oelkers. "The redistribution of responsibility between state and parents: Family in the context of post-welfare-state transformation.” In The Politicization of Parenthood. Edited by Martina Richter and Sabine Andresen. Heidelberg/London: Springer, 2012, pp. 101-10.

49. Rik Peeters, and Gerard Drosterij. "Verantwoordelijke vrijheid. Responsabilisering van burgers op voorwaarden van de staat.” Tijdschrift voor Beleid, Politiek en Maatschappij 38 (2011): 179-99.

50. Michel Foucault. Security, Territory, Population. Lectures at the College de France 1977-1978. New York: Picador, 2007, p. 464.

51. John Harris. The Social Work Business. London: Routledge, 2003, p. 240.

52. Harry Kunneman. Voorbij het dikke-ik. Bouwstenen voor een kritisch humanisme. Amsterdam: SWP, 2005, p. 287. (In Dutch)

53. Rami Benbenishty, Rujla Osmo, and Nora Gold. "Rationales Provided for Risk Assessments and for Recommended Interventions in Child Protection: A Comparison between Canadian and Israeli Professionals.” British Journal of Social Work 33 (2003): 137-55.

54. Rudi Roose, Griet Roets, and Maria Bouverne-De Bie. "Irony and Social Work: In Search of the Happy Sisyphus.” British Journal of Social Work 42 (2012): 1-16.

55. Brian Littlechild. "Child protection social work: Risks of fears and fear of risks-Impossible tasks from impossible goals.” Social Policy and Administration 42 (2008): 662-75.

56. Rijksoverheid. Available online: http://www.rijksoverheid.nl/documenten-en-publicaties/ rapporten/2013/11/12/risico-regelreflex-in-de-jeugdzorg.html (accessed on 1 June 2014).

57. Andres Turnell, and Steve Edwards. Signs of Safety: A Safety and Solution Oriented Approach to Child Protection Casework. New York: W. W. Norton, 1999, p. 45.

(C) 2014 by the authors; licensee MDPI, Basel, Switzerland. This article is an open access article distributed under the terms and conditions of the Creative Commons Attribution license (http://creativecommons.org/licenses/by/4.0/) 